\title{
The Evaluation System of Enterprise Tacit Knowledge Management Performance
}

\author{
Liu Yang \\ College of Economics and Management \\ Dalian University \\ Dalian, 116622, China \\ 1_y_apple@163.com
}

\begin{abstract}
Accurate measure and reasonable evaluation of tacit knowledge management performance is the foundation of managing tacit knowledge effectively. This paper establishes the corresponding performance evaluation index system of tacit knowledge resources system, tacit knowledge management process, and tacit knowledge management situation system on the basis of the whole structure of enterprise tacit knowledge management system, in addition researches the measure of enterprise tacit knowledge resources for the reserves of tacit knowledge and establishes indicators to measure respectively from three levels of the core layer, the layer structure and the implicit layer, which presents an evaluation method of enterprise tacit knowledge reserves.
\end{abstract}

Keywords-tacit knowledge management; performance evaluation; measure index; situation system; resources

\section{INTRODUCTION}

The performance evaluation of enterprises tacit knowledge management refer to a comprehensive evaluation about tacit knowledge resources in the production and business operation that enterprise relies on, a series of management activities that include the accumulation of tacit knowledge resources , sharing and application and so on, and the degree that the corresponding management situation can achieve on all aspects inside and outside the organization. The performance evaluation of enterprises tacit knowledge management can reflect the status of an enterprise tacit knowledge management, can also reflect the enterprise's future development trend, and is an important way that the enterprise understands their tacit knowledge management level, which make enterprise do longitudinal comparison to itself tacit knowledge management level or do horizontal comparison with related enterprises, in order to better use and give full play to the advantages of existing tacit knowledge[1].

Research literature about the tacit knowledge management evaluation is not much at home and abroad. Some scholars have studied the knowledge management performance evaluation and some other scholars establish the index system on an aspect of tacit knowledge management process, which have their own characteristics, play a role to develop or improve the tacit knowledge management evaluation research [2,3]. However, research results on tacit knowledge management performance evaluation is absent and at the same time the research of organizational tacit knowledge measure problem is less, which focus on measurement of individual tacit knowledge reserve. But the enterprise tacit knowledge resources reserve is the foundation and the target of the tacit knowledge management and the measurement of enterprise tacit knowledge reserve is more important. So there are still a lot of problems that need to be researched about the assessment of tacit knowledge management. According to the theoretical research, this paper designs the performance evaluation index system of tacit knowledge management, and has tacit knowledge performance evaluation from three aspects of the resources, processes, and environment to provide decision-making basis for guiding the development of the enterprise tacit knowledge[4].

\section{THE ESTABLISHMENT OF THE ENTERPRISE TACIT KNOWLEDGE MANAGEMENT PERFORMANCE EVALUATION SYSTEM}

\section{A. Index System Table of Enterprises Tacit Knowledge Management Performance Evaluation}

According to the principles of systematic, gradation, segmentation, operability and comparability, predictability, and combination of qualitative and quantitative design, performance evaluation index system of enterprise tacit knowledge management is designed based on the components of tacit knowledge management performance evaluation and the specific evaluation index system is listed out in table 1 .

TABLE I. INDEX SYSTEM TABLE OF ENTERPRISES TACIT KNOWLEDGE MANAGEMENT PERFORMANCE EVALUATION

\begin{tabular}{|c|c|c|}
\hline $\begin{array}{l}\text { The target } \\
\text { layer }\end{array}$ & $\begin{array}{l}\text { The main } \\
\text { criterion layer }\end{array}$ & Sub-criterion Layer \\
\hline \multirow{11}{*}{$\begin{array}{l}\text { index system } \\
\text { of tacit } \\
\text { knowledge } \\
\text { resources } \\
\text { (U1) }\end{array}$} & \multirow{3}{*}{$\begin{array}{l}\text { the core layer } \\
\text { (U11) }\end{array}$} & enterprise technology secret \\
\hline & & organize language \\
\hline & & organizational identification \\
\hline & \multirow{3}{*}{$\begin{array}{l}\text { the structure } \\
\text { layer (U12) }\end{array}$} & $\begin{array}{l}\text { the abundance of enterprise tacit } \\
\text { knowledge base }\end{array}$ \\
\hline & & $\begin{array}{l}\text { the average daily number of valid } \\
\text { theme in knowledge community }\end{array}$ \\
\hline & & $\begin{array}{l}\text { the matching degree of knowledge } \\
\text { map and knowledge base, and the } \\
\text { matching degree of experts and } \\
\text { knowledge community }\end{array}$ \\
\hline & \multirow{5}{*}{$\begin{array}{l}\text { the implicit } \\
\text { layer (U13) }\end{array}$} & professional technical ability \\
\hline & & $\begin{array}{l}\text { the ability of learning and } \\
\text { innovation }\end{array}$ \\
\hline & & $\begin{array}{l}\text { the ability communication and } \\
\text { cooperation }\end{array}$ \\
\hline & & the ability of problem solving \\
\hline & & empathic ability \\
\hline
\end{tabular}




\begin{tabular}{|c|c|c|}
\hline \multirow{9}{*}{$\begin{array}{l}\text { management } \\
\text { process } \\
\text { indicators } \\
\text { (U2) }\end{array}$} & \multirow{3}{*}{$\begin{array}{l}\text { the ability of } \\
\text { tacit } \\
\text { knowledge } \\
\text { accumulation } \\
\text { (U21) }\end{array}$} & $\begin{array}{l}\text { the establishment of the external } \\
\text { knowledge alliance }\end{array}$ \\
\hline & & $\begin{array}{l}\text { recognition of the Tacit } \\
\text { knowledge }\end{array}$ \\
\hline & & the coding of tacit knowledge \\
\hline & \multirow{3}{*}{$\begin{array}{l}\text { tacit } \\
\text { knowledge } \\
\text { sharing } \\
\text { (U22) }\end{array}$} & $\begin{array}{l}\text { the perfect degree of the network } \\
\text { connection mechanism }\end{array}$ \\
\hline & & close cooperation relationships \\
\hline & & $\begin{array}{l}\text { the level of tacit knowledge } \\
\text { sharing channels }\end{array}$ \\
\hline & \multirow{3}{*}{$\begin{array}{l}\text { the application } \\
\text { ability of tacit } \\
\text { knowledge } \\
\text { (U23) }\end{array}$} & $\begin{array}{l}\text { the integration capability of tacit } \\
\text { knowledge }\end{array}$ \\
\hline & & $\begin{array}{l}\text { the use of employees tacit } \\
\text { knowledge }\end{array}$ \\
\hline & & $\begin{array}{l}\text { the innovation decision-making } \\
\text { ability of the management }\end{array}$ \\
\hline \multirow{10}{*}{$\begin{array}{l}\text { situational } \\
\text { system } \\
\text { indicators } \\
\text { (U3) }\end{array}$} & \multirow{4}{*}{$\begin{array}{l}\text { organization } \\
\text { situation } \\
\text { (U31) }\end{array}$} & leadership support \\
\hline & & $\begin{array}{l}\text { organizational innovation } \\
\text { mechanism }\end{array}$ \\
\hline & & $\begin{array}{l}\text { the knowledge-based of } \\
\text { organizational structure }\end{array}$ \\
\hline & & $\begin{array}{l}\text { the capacity of resources } \\
\text { allocation }\end{array}$ \\
\hline & \multirow{3}{*}{$\begin{array}{l}\text { technical } \\
\text { situation } \\
\text { (U32) }\end{array}$} & $\begin{array}{l}\text { maturity of Information technology } \\
\text { platform }\end{array}$ \\
\hline & & $\begin{array}{l}\text { the openness of physical facilities } \\
\text { planning }\end{array}$ \\
\hline & & advanced production equipment \\
\hline & \multirow{3}{*}{$\begin{array}{l}\text { cultural } \\
\text { situation } \\
\text { (U33) }\end{array}$} & the core values of the organization \\
\hline & & behavior standards of employee \\
\hline & & enterprise cohesion \\
\hline
\end{tabular}

\section{B. The Measure Indexes of Tacit Knowledge Resources}

The measure of tacit knowledge resources system is based on enterprise tacit knowledge reserve. Enterprise tacit knowledge reserve refers to the amount of enterprise tacit knowledge in a certain point and is the integrated tacit knowledge that is attached to the enterprise internal staff, team and organizational structure all, which is the result of learning. Tacit knowledge need to be further divided to measure tacit knowledge reserve. This article divides tacit knowledge resources system into three levels: according to value target of the enterprises tacit knowledge management, that is the core layer, the structure layer and the hidden layer, which can be measured by the following indexes respectively.

\section{1) The tacit knowledge reserve of the core layer}

Core layer refers to the knowledge reserve that forms core competitive ability of the enterprise, which includes the unique products, unique technology, unique marketing means, the unique enterprise culture advocated and so on ,which is difficult to be imitated by competitors and dependent on enterprise layer. We use three indicators of enterprise technology secret, organization language, group identity to measure [5].

2) The tacit knowledge reserve of the structure layer

The tacit knowledge reserve of the structure layer is the knowledge about goals and achieving sub-targets behavior (methods) that exist in knowledge base of the organization, equipment, software, products and management system and so on and are shared by the organize members[6].

3) The tacit knowledge reserve of implicit layer

The tacit knowledge reserve of implicit layer is tacit knowledge accumulation of all enterprises professional personnel, which can measure level of skills and experience of the professional personnel. Because most of the tacit knowledge exists in the individual, the measurement of implicit layer of tacit knowledge makes individual as the center and adopts the method of subjective evaluation to measure each kind of tacit knowledge. Measure of tacit knowledge can set up corresponding evaluation index to appraise according to different industries or through the simulation test and psychological tests, etc. Each specific industry experts set the weights of the above indicators and the specialist personnel should be from three layers of high, medium and low of enterprise that is the corresponding senior policymakers, middle managers, and lower senior employees[7].

For the level setting of each type of knowledge, different enterprises can adopt different standards, the following table 2 shows a standard:

TABLE II. TACIT KNOWLEDGE LEVELS

\begin{tabular}{|c|c|}
\hline Level & Description \\
\hline 1 & Novice: practice knowledge only stiffly and out of the use \\
\hline 2 & Between level 1 and level 3 \\
\hline 3 & $\begin{array}{l}\text { Senior introduction person: has the ability of using } \\
\text { knowledge appropriately according to actual condition, } \\
\text { help understanding the task by limited work experience, } \\
\text { but not understanding the key of the task. }\end{array}$ \\
\hline 4 & Between level 3 and level 5 \\
\hline 5 & $\begin{array}{l}\text { The competent person: makes task goal as guide, and } \\
\text { carries on the detailed plan for this, can understand the key } \\
\text { of tasks, can cope with emergencies, but also lacks speed } \\
\text { and flexibility. }\end{array}$ \\
\hline 6 & Between level 5 and level 7 \\
\hline 7 & $\begin{array}{l}\text { Master: to be able to complete the task in combination with } \\
\text { his own instincts, can plan and adjust the task overall } \\
\text { according to the current situation and the past experience }\end{array}$ \\
\hline 8 & Between level 7 and level 9 \\
\hline 9 & $\begin{array}{l}\text { Expert: working directly relying on intuition and without } \\
\text { conscious thought, and its behavior is continuing and } \\
\text { spontaneous. }\end{array}$ \\
\hline
\end{tabular}

In the actual measurement, each level of the above nine knowledge level can be set the corresponding weights, in order to form the weight vector W. For different industries and different departments weight vector may be different. In a certain time $\mathrm{T}$, Individuals can determine their level to form a matrix that is set to Lt for each class of individual tacit knowledge, and then enterprises or departments can statistic the number of each class, and Next change it into the matrix of $\mathrm{N}_{\mathrm{t}}$, in order to you can corresponding individual tacit knowledge reserve level in a certain period of time $\mathrm{t},\left(\right.$ The vector is set to $\mathrm{P}_{\mathrm{t}}$ ) and the tacit knowledge reserve of enterprise or department level(the vector set to $\mathrm{S}_{\mathrm{t}}$ ).

$$
\begin{gathered}
P_{t}=L_{t} \times W \\
S_{t}=N_{t} \times W
\end{gathered}
$$

For example, rating of tacit knowledge reserve of an employee of is listed in the table 3. When a company or department measure tacit knowledge stock, each kind of knowledge can is got by counting the number of each level, such as table 4 . 
TABLE III. EVALUATION OF AN EMPLOYEE'S TACIT KNOWLEDGE RESERVE

\begin{tabular}{|c|c|c|c|c|c|c|c|c|c|}
\hline $\begin{array}{l}\text { Level } \\
\text { Types of knowledge }\end{array}$ & 1 & 2 & 3 & 4 & 5 & 6 & 7 & 8 & 9 \\
\hline professional skill ability & & & & & $\sqrt{ }$ & & & & \\
\hline learning and innovation ability & & & & & & $\sqrt{ }$ & & & \\
\hline $\begin{array}{l}\text { the ability of communication and } \\
\text { cooperation }\end{array}$ & & & & & & & & $\sqrt{ }$ & \\
\hline empathic ability & & & & & & & $\sqrt{ }$ & & \\
\hline
\end{tabular}

TABLE IV. ASSESSMENT OF AN ENTERPRISE (OR DEPARTMENT) TACIT KNOWLEDGE RESERVE

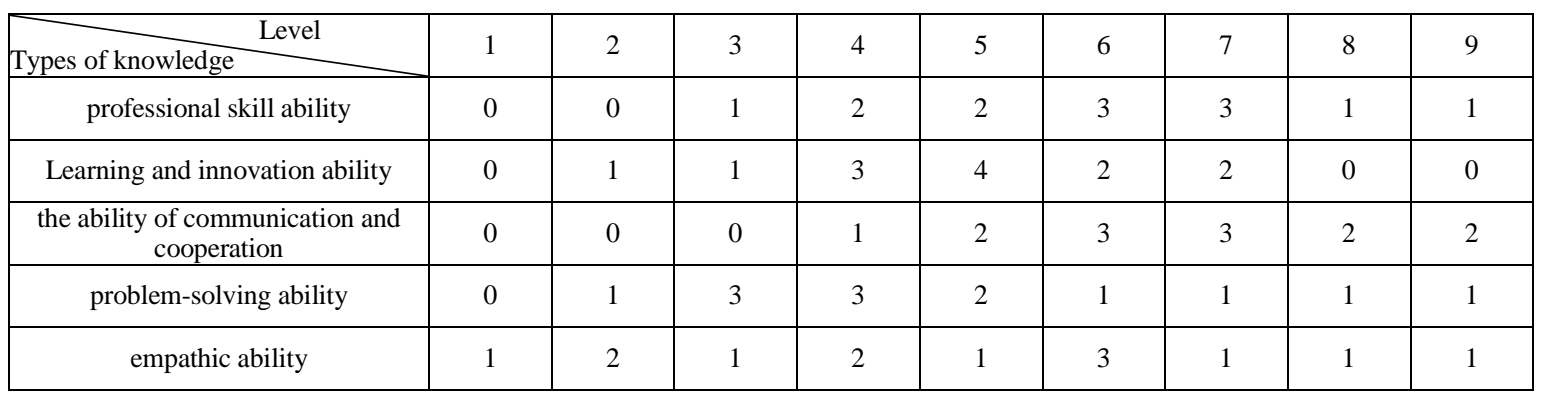

Table 3 and table 4 are converted into the corresponding matrix:

$$
\begin{aligned}
L_{t} & =\left[\begin{array}{lllllllll}
0 & 0 & 0 & 0 & 1 & 0 & 0 & 0 & 0 \\
0 & 0 & 0 & 0 & 0 & 1 & 0 & 0 & 0 \\
0 & 0 & 0 & 0 & 0 & 0 & 0 & 1 & 0 \\
0 & 0 & 0 & 0 & 0 & 1 & 0 & 0 & 0 \\
0 & 0 & 0 & 0 & 0 & 0 & 1 & 0 & 0
\end{array}\right] \\
N_{t} & =\left[\begin{array}{lllllllll}
0 & 0 & 1 & 2 & 2 & 3 & 3 & 1 & 1 \\
0 & 1 & 1 & 3 & 4 & 2 & 2 & 0 & 0 \\
0 & 0 & 0 & 1 & 2 & 3 & 3 & 2 & 2 \\
0 & 1 & 3 & 3 & 2 & 1 & 1 & 1 & 1 \\
1 & 2 & 1 & 2 & 1 & 3 & 1 & 1 & 1
\end{array}\right]
\end{aligned}
$$

Here weight is set to simply:

$$
W=\left[\begin{array}{lllllllll}
0.1 & 0.2 & 0.3 & 0.4 & 0.5 & 0.6 & 0.7 & 0.8 & 0.9
\end{array}\right]^{\prime} \text {, then }
$$

$$
\begin{aligned}
& P_{t}=L_{t} \times W=\left[\begin{array}{ccccccccc}
0 & 0 & 0 & 0 & 1 & 0 & 0 & 0 & 0 \\
0 & 0 & 0 & 0 & 0 & 1 & 0 & 0 & 0 \\
0 & 0 & 0 & 0 & 0 & 0 & 0 & 1 & 0 \\
0 & 0 & 0 & 0 & 0 & 1 & 0 & 0 & 0 \\
0 & 0 & 0 & 0 & 0 & 0 & 1 & 0 & 0
\end{array}\right] \times \\
& {\left[\begin{array}{lllllllll}
0.1 & 0.2 & 0.3 & 0.4 & 0.5 & 0.6 & 0.7 & 0.8 & 0.9
\end{array}\right]^{\prime}=\left[\begin{array}{l}
0.5 \\
0.6 \\
0.8 \\
0.6 \\
0.7
\end{array}\right]} \\
& P_{t}=L_{t} \times W=\left[\begin{array}{ccccccccc}
0 & 0 & 0 & 0 & 1 & 0 & 0 & 0 & 0 \\
0 & 0 & 0 & 0 & 0 & 1 & 0 & 0 & 0 \\
0 & 0 & 0 & 0 & 0 & 0 & 0 & 1 & 0 \\
0 & 0 & 0 & 0 & 0 & 1 & 0 & 0 & 0 \\
0 & 0 & 0 & 0 & 0 & 0 & 1 & 0 & 0
\end{array}\right] \times
\end{aligned}
$$$$
\left[\begin{array}{lllllllll}
0.1 & 0.2 & 0.3 & 0.4 & 0.5 & 0.6 & 0.7 & 0.8 & 0.9
\end{array}\right]^{\prime}=\left[\begin{array}{l}
0.5 \\
0.6 \\
0.8 \\
0.6 \\
0.7
\end{array}\right]
$$

Tacit knowledge ability level of employees' overall can be seen as vectors by the method, which can reflect comprehensive scientific knowledge level of the enterprise as evaluate the enterprise knowledge level. But vector can be handled by a lot of mathematical methods, Therefore it can be used as the basis of many related research. At the same time, index of different categories knowledge can form according to the measurement result. When 
department is formed and talent is selected, personnel number of the levels can be determined by means of linear programming or overall planning. We can find complementary of knowledge among enterprise, enterprise internal departments or individual $b$ calculate the gap between the vectors, In order to adopt corresponding strategies to promote the knowledge exchange between them.

\section{The Evaluation Index of the Tacit Knowledge Management Process}

Tacit knowledge management process involves accumulation, sharing and the specific implementation of application of tacit knowledge. So, this paper extracted the three key indicators to evaluate the tacit knowledge management process accordingly that is tacit knowledge accumulation ability, the ability of tacit knowledge sharing, tacit knowledge application ability. Three secondary indexes need to be further decomposed.

1) Tacit knowledge accumulation ability

The accumulation of tacit knowledge mainly refers to the acquisition of external tacit knowledge and the conversion of internal tacit knowledge, by innovating gradually new tacit knowledge obtained and created gradually, Such as experience summary report, technical documentation, instruction manual, patent document, etc. So we use the following indicators in evaluating tacit knowledge accumulation [8].

- The establishment status of the external knowledge alliance: the utilization degree of tacit knowledge of suppliers, customers, research institutes and rival.

- Recognition of the tacit knowledge: perception and acquisition of tacit knowledge of knowledge source, and the selection of knowledge experts.

- The coding of tacit knowledge: processing the tacit knowledge and making it enter the enterprise knowledge base by the methods of language, text symbols, calculating program and so on to become the knowledge assets of enterprise.

2) The ability of Tacit knowledge sparing

The implementation of tacit knowledge involves the design of tacit knowledge sharing channel and the mechanism system, so this paper chooses the following three level 3 indicators to evaluate enterprises tacit knowledge sharing.

- The perfect degree of the network connection mechanism: informal communication channels, formal team cooperation, and the construction of the practice community;

- Close cooperation relationships: the level of tacit knowledge sharing channels, that is, Including the employee's informal communication frequency and mutual trust.

- The level of tacit knowledge sharing channels: the efficiency of reducing the searching time and cost of employee by the document management system and expert system.

3) The application ability of Tacit knowledge

The indicator is used for evaluating implementation of tacit knowledge management. The paper presents the realization model of tacit knowledge from three aspects, which is tacit knowledge utilization of the employees, cooperative $\mathrm{R} \& \mathrm{D}$, and management decision making. So in this paper evaluates it by setting the following three secondary indicators [9].

- The integration capability of tacit knowledge: coordination ability in a specific task to the workers to have specialized knowledge;

- The use of employee tacit knowledge: employees use tacit knowledge to improve work efficiency;

- The innovation decision-making ability of the management:

- Managers do intuitive judgment in order to realize effective innovation decision-making based on tacit knowledge.

\section{The Situational System Indicators of Tacit \\ Knowledge Management}

Situational system provides protection for continuous running of enterprise tacit knowledge management. This paper divides the primary index of situational system into three secondary indicators of organization situation, material technology situation and cultural situation. Through the evaluation of enterprise tacit knowledge management situation, advantages and disadvantages at the basic level of tacit knowledge management can be found.

1) Organization situation indicators

- Leadership support: Leader understanding about the importance of knowledge, the formulation and implementation of tacit knowledge management planning;

- Organizational innovation mechanism: To encourage the learning and innovation, and staff motivation of tacit knowledge sharing;

- The knowledge-based of organization structure: the setting of knowledge management department and the CKO, reduction of organization hierarchy, the people-centered humanized management, and the channels of communication between peers or superiors.

- The capacity of resources allocation: employees can get more abundant in work life activity funds, the large amount of information, performance and development opportunities inside and outside enterprise, time of thinking freely and other material or intangible resources.

2) Material technology situation indicators

- Maturity of Information technology platform: The establishment of knowledge map, the construction of the expert network system, and the establishment of knowledge base;

- The openness of physical facilities planning: Office area to open set, and provide staff rest area of the communication;

- Progressiveness of production equipment: the skill level of production equipment that companies have, and the experimental apparatus.

3) Cultural situation indicators

- The core values of the organization: reflecting that knowledge of unique culture level that the enterprise have and the degree of identifying the enterprise values, organizational goals, and the way of management. 
- Behavior standards of employee: Code of conducts and behavior that is designed by organization and reflects the enterprise values.

- Enterprise cohesion: employee attitude, employee satisfaction, organization symbiotic and coordination and dependency of organization [10].

\section{CONCLUSIONS}

How to evaluate performance of the enterprises tacit knowledge management is of great significance to strengthen the enterprises tacit knowledge management and promote the formation of enterprise core competence. Tacit knowledge has the characteristics "hidden, not coding, highly personalized", and is more difficult to measure than the explicit knowledge. At present, although some scholars have made some research on the enterprise knowledge management evaluation, there is no in-depth study on the problem of tacit knowledge management performance measurement [11].This paper establishes the corresponding performance evaluation index system including tacit knowledge resources system, tacit knowledge management process, and tacit knowledge management situation system on the basis of the whole structure of enterprise tacit knowledge management system. Evaluation index system of the tacit knowledge management performance that is put forward, is put more attention to the particularity of tacit knowledge management system, and the index system considers the requirements of tacit knowledge management system from two aspects of qualitative and quantitative, which make evaluation result more scientific and objective.

\section{ACKNOWLEDGMENT}

The research work was supported by Humanities and Social Science Foundation of Education Department of Liaoning province under Grant No. W2013276. and Social
Science Foundation of Social Science Association of Liaoning Province under Grant No. 20131slktzjjx-10.

\section{REFERENCES}

[1] Tsai W., "Knowledge transfer intra-organizational networks: Effects of network position and absorptive capacity on business unit innovation and performance ,"Academy of Management Journal, vol.16,2007, pp.36-44.

[2] Kristian Kreiner, "Tacit knowledge management: the role of artifacts,'Journal of Knowledge Management, vol6,pp.65-78.

[3] Michael Fitzgerald., "At risk offshore , US companies outsourcing their software development offshore can get stung by industrial espionage and poor intellectual property safeguards,"CIO,vol17,2003,pp.1-2.

[4] Daniel Gervais, "Traditional Knowledge \& Intellectual Property: A Trips-Compatible Approach," Detroit College of Law Michigan State Law Review, Spring 2005,pp.137-166.

[5] Anna T. Cianciolo, Elena L. Grigorenko, Linda Jarvin, et al. , "Practical Intelligence and Tacit Knowledge: Advancements in the Measurement Of Developing Expertise,'Learning and Individual Differences, vol.16,2006,pp.235-253.

[6] Jean Raymond Homere, "Intellectual Property Rights Can Help Stimulate the Economic Development of Leas Developed Countries," The Columbia Journal of Law\& the Arts , vol.27,2004,pp.277-299.

[7] Mark A.Lemley, "Property, Intellectual Property, and Free Riding,” Texas Law Review,vol.83,2005,pp.1031-1075.

[8] Ruth.M.Corbin,"Managing risk and protecting intellectual property,’Ivey Business Journal, vol,66,2002,pp.11-14.

[9] Kaz Miyagiwa,Yuka Ohno, "Uncertainty, spillovers and cooperative R\&D,"International Journal of Industrial Organization, vol.20,2002,pp.855-876.

[10] Kaz Miyagiwa,Yuka Ohno, “ How knowledge attributes influence alliance governance choices: A theory development Note,'.Journal of International Management, vol.8, 2002,pp.11 27.

[11] B.R.,"Montano Etc.A systems thingking framework for knowledge management,".Decision Suspport Systems,vol.31, 2001,pp.5-16. 